\title{
Brief Review on Some Major Factors Affecting Visible Light Activity of Titania Photocatalyst
}

\author{
Burtrand I Lee \\ Department of Materials Science of Engineering, Clemson University, Clemson, SC, USA.
}

Review Article

\begin{abstract}
As sunlight is an excellent source of clean energy, research for harnessing the energy via an efficient photocatalyst that is active under visible light is actively underway. Titania is well accepted as a photosemiconductor and photocatalyst under ultraviolet light. Effort to make it visible light active has been growing. This review article presents some factors involving the photocatalytic activity of titania which is active under visible light in terms of crystallography. Based on recent progress, several suggestions are made for a better visible light active titania.
\end{abstract}

Keywords: Titania; Photocatalyst; Visible Light; Crystal Lattice; Hetero Junction; Excitons; Charge Separation.

\author{
*Corresponding Author: \\ Burtrand I Lee, \\ Department of Materials Science of Engineering, Clemson University, \\ Clemson, SC 29634, USA. \\ E-mail: lburtra@yahoo.com
}

Received: September 10, 2014

Accepted: October 23, 2014

Published: October 25, 2014

Citation: Burtrand I Lee (2014) Brief Review on Some Major Factors Affecting Visible Light Activity of Titania Photocatalyst. Int J Nano Stud Technol. 3(5), 67-71. doi: http://dx.doi.org/10.19070/2167-86851400013

Copyright: Burtrand I Lee 2014 This is an open-access article distributed under the terms of the Creative Commons Attribution License, which permits unrestricted use, distribution and reproduction in any medium, provided the original author and source are credited.

\section{Introduction}

Titania is well known for its usefulness as a photocatalyst under ultraviolet light (UV). For more practical and broader applications, the photocatalytic activity (PCA) under visible light (VL) has been actively pursued over a decade. Interest in VL active photocatalysis has been motivated in part by the realization that sunlight is effectively an inexhaustible energy source. Most frequent effort to boost visible light photocatalytic activity (VLA) included doping the titania crystal lattice. More successes have been shown by anions and nitrogen in particular [1-3]. hydrogenated titania surface and increased the solar absorption. Dye-sensitization technique [4-6] is well utilized. Surface incorporation of high electrical conductivity metal nanoparticles is well known for its surface plasmonics [7-10].

For high PCA, one of the requirements for a catalyst is high specific area (SSA). In the synthesis of high SSA nanoparticles, one chooses to use a low temperature method such as solution or sol- gel process. A dilemma encountered in this is that the particles produced at a low temperature contain much residual impurities such as water $\left(\mathrm{H}^{+}, \mathrm{H}_{2} \mathrm{O}, \mathrm{OH}^{-}, \mathrm{H}_{3} \mathrm{O}^{+}\right)$, solvent, and any additives that had to be present to optimize the process $[11,12]$. Conventionally these are removed by the subsequent calcinations steps which are also used to promote crystallinity. These steps involving elevated temperatures will cause the surface area reduction as well as any unwanted phase transformation. This may be overcome by nonaqueous solution process followed by low temperature drying or dehydration processes [12-19].

Another major factor known to affect the PCA is efficient separation of the photogenerated charges, i.e., exctions of $\mathrm{e}^{-\mathrm{s}}$ and $\mathrm{h}^{+} \mathrm{s}$. Heterojunctions are shown to be effective site in reducing the recombination rates of the photogenerated $e^{-s}$ and $h^{+} s[13,20-$ 32]. Heterointerfaces between crystallographic phases are critical to many photocatalyses including solar energy conversion. Understanding structure/composition at the metal/metal oxide or metal oxide/metal oxide interfaces, the ability to tailor and tune those interfaces are then essential elements in developing more efficient photocatalysts [28-32]. In this review article, the major factors contributing to the VLA are mentioned and crystallographic features directly related to VLA are discussed.

Titania is known to have three polymorphs: Anatase (An), rutile $(\mathrm{Ru})$, and brookite $(\mathrm{Br})[33,34]$. These three $\mathrm{TiO}_{2}$ crystallographic phases have similar chemical properties, but have different crystalline structures. An and $\mathrm{Ru}$ are tetragonal, whereas $\mathrm{Br}$ is orthorhombic [33]. An phase $\mathrm{TiO}_{2}$ is photocatalytically the most active under UV [29,33-37]. At an ambient condition, $\mathrm{Ru} \mathrm{TiO}_{2}$ is thermodynamically the most stable phase [33-35]. An is most widely utilized as photocatalyst under UV because it exhibits the highest SSA with an ease of production [33-35]. As one calcines $\mathrm{An}$, it begins to transform to $\mathrm{Ru}$ at a temperature near $400^{\circ} \mathrm{C}$ depending on the SSA and/or the crystallite size [33]. $\mathrm{Br}$ phase is metastable, least well known, and is the most difficult to synthesize [33-35]. There are conflicting reports on the photo- 
catalytic properties of $\mathrm{Br}$ phase of titania [33-40]. Some claim $\mathrm{Br}$ is the most photocatalytically active [34,38-40] and some report An is [28]. However, An exhibits the largest band gap energy and hence the least active under VL. A low temperature solution process often yields mixed phase of titania with different proportions depending on the experimental variables [11,33,38,39]. By varying the synthesis conditions, e.g., time, temperature, and $\mathrm{pH}$, the polymorphic phases in titania can be controlled $[11,33,38,39]$.

Along the line can a mixed phase titania be more photocatalytically active than a single or pure phase An? Based on hetrojunctions promoting the charge transport in the excitons across the phase boundary, a mixed phase structure could be more photocatalytically active [35]. One well known example of this is Degussa Aeroxide $\mathrm{TiO}_{2}$, also known as P25, which consists of $79 \%$ An and $21 \% \mathrm{Ru}[41]$.

\section{Results and Discussion}

A low temperature synthesis method, called the "water based ambient condition sol" (WACS) process, yielded well crystallized high surface area polymorphic nanoparticle titania with $\mathrm{Br}$ as the predominant phase $[11,33,38,39]$. However, this water based low temperature synthesis method incorporates water or protons from the solvent water into the lattice $[11,33,38,39]$ as shown in Figure 1. The extraneous protons will create cation vacancies, e.g., $4 \mathrm{H}^{+}$ions creating $1 \mathrm{Ti}^{4+}$ ion vacancy by the charge neutrality principle. Upon calcination the protons bonded to oxygen anions can be removed as water by the reaction $2 \mathrm{OH} \rightarrow \mathrm{H}_{2} \mathrm{O}+\mathrm{O}^{2-}$. Removing the lattice protons and/or synthesis in a lesser water environment has enhanced optical [42], dielectric [43-47], and/or catalytic properties in other metal oxides $[17,47,48]$.
A polymorphic titania with $\mathrm{Br}$ as the major phase, i.e., polymorphic brookite Titania (PBT) - produced by WACS process [11-14] followed by a post-treatment in hot N-methylpyrrolidone (NMP) solvent, labeled as SACS200 - is shown to much enhance VLA [12-14]. Table 1 lists the titania samples discussed in this review with the corresponding phase compositions, crystallite sizes, and SSAs of PBT as compared with other reference titanias. Figure 2 shows UV-Vis spectra of these titania [38]. PBT200 which is titania with $53 \% \mathrm{Br}$ and $45 \%$ An before the proton extraction shows some VL absorption while NMP treated PBT, i.e., SACS200 showed much increased VL absorption. Postech $\mathrm{TiO}_{2}$ that is $\mathrm{N}$-doped An titania showed some VL absorption while P25 showed no VL absorption. Nanoparticle titania with crystallite size $<10 \mathrm{~nm}$ of $\mathrm{Br}$ as the predominant phase exhibits a moderate VL absorption. A polar anhydrous solvent NMP treatment of PBT enhanced VLA significantly. These titanias tested for photocatalytic degradation of methyl orange (MO) under VL irradiation with a $14 \mathrm{~W}$ fluorescent lamp are shown in Figure 3 [12]. SACS200 which is An/Br mixed phase shows superior VLA to NMP treated $\mathrm{TiOz}$ (TiOzSACS200) despite its higher SSA. The difference between the two titanias is that SACS200 is An/ Br mixture and TiOzSACS200 is single phase An. P25 treated with NMP (not shown here) hardly showed any enhanced VLA [12-14]. This means that the superior VL PCA of SACS200 must be attributable to the mixed phase of $\mathrm{Br}$ and $\mathrm{An}$.

The superior VL photocatalytic activity was explained as the effective charge separation by the intercrystalline electron transport from $\mathrm{Br}$ to An grains complemented by the strong VL absorption with the nitrogen species incorporated from NMP. The NMP here had a dual role of removing the entrapped protons from the crystal lattice of titania and introducing VL absorbing nitrogen

Figure 1. Protonated Titania crystal lattice from WACS process

TITANium
OXYGen

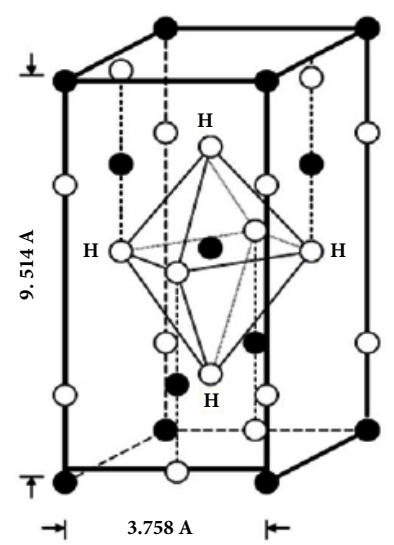

Table 1. Titania samples with phase compositions, the corresponding crystallite sizes, and specific surface areas

\begin{tabular}{|c|c|c|c|c|}
\hline & Phase conten & & te size in $\mathrm{nm}$ & BET surface area \\
\hline Sample ID & An & $\mathrm{Br}$ & $\mathbf{R u}$ & $\mathrm{m}^{2} / \mathrm{g}$ \\
\hline РBT200 & 45,6 & 53,7 & 2,18 & 157 \\
\hline SACS200 & 44,6 & 53,8 & 3,11 & 138 \\
\hline P25 & 79,21 & - & 21,40 & 56 \\
\hline Postech, N-doped & 100,22 & - & - & 93 \\
\hline TiOzSACS200 & 100,7 & - & - & 173 \\
\hline HBK & 100,9 & - & - & 200 \\
\hline
\end{tabular}


Figure 2. UV-Visible spectra of various titanias

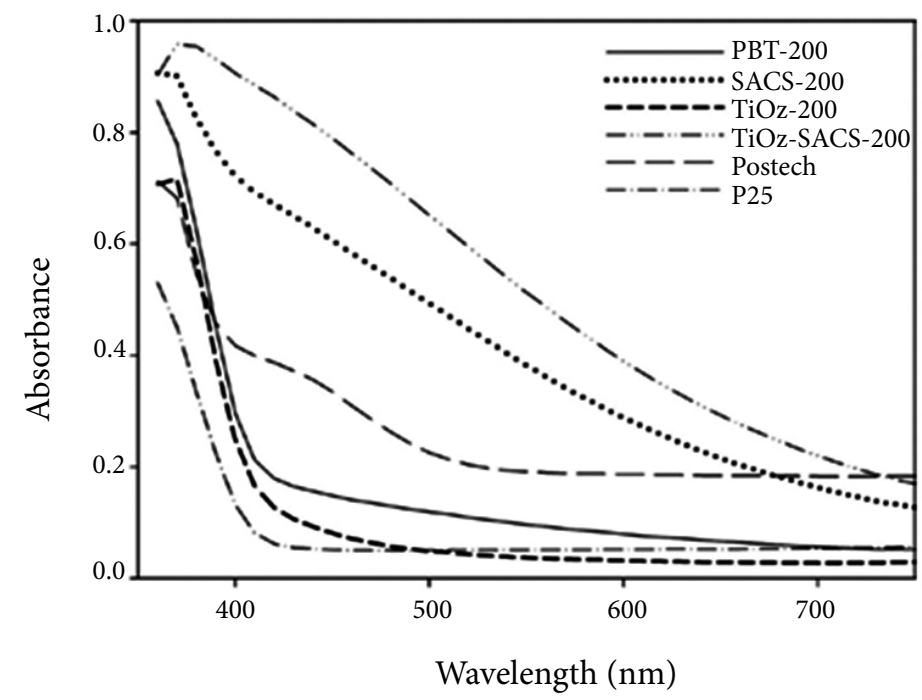

Figure 3. Degradation rate of methyl orange dye by VL photocatalytic action of various titanias.

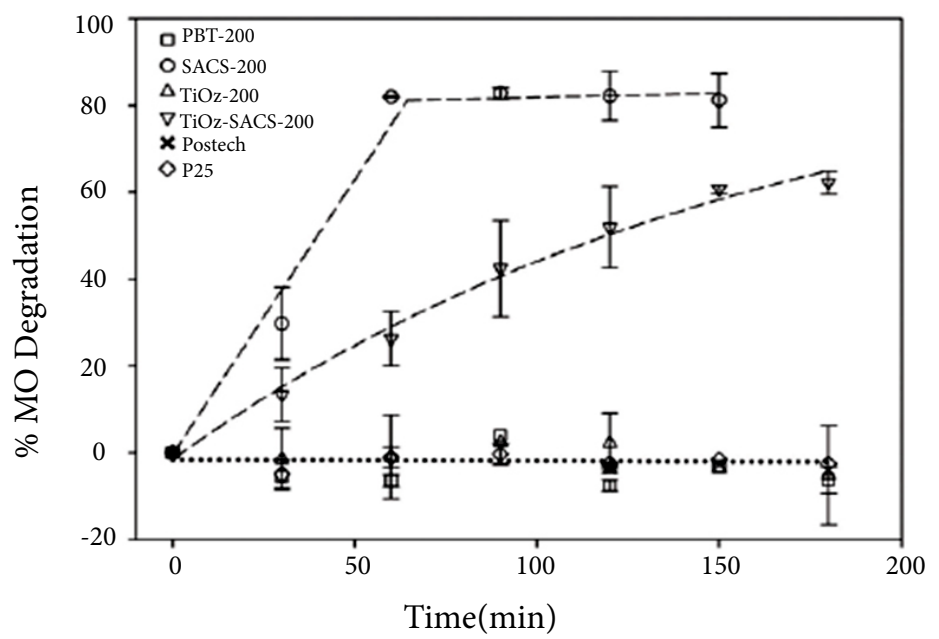

Figure 4. Solid state 1H MAS NMR spectra of (a) before NMP treatment and b) after NMP treatment of PBT.

(a)

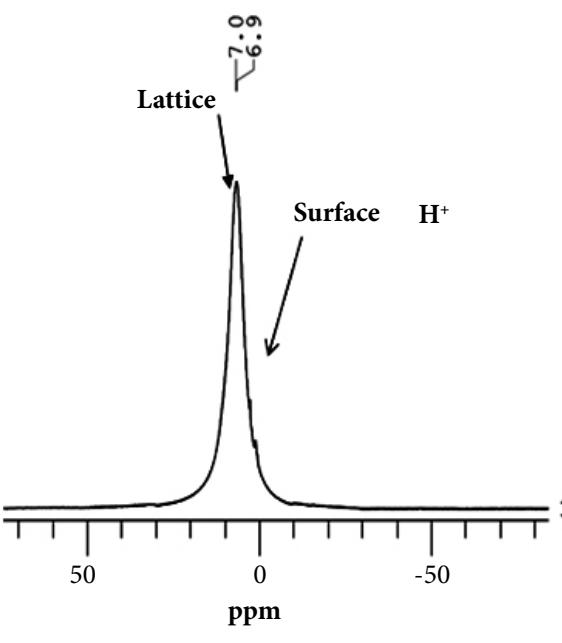

doping effect. These lattice protons extracted by NMP at a low temperature was confirmed by TGA, FTIR and solid state proton MAS-NMRspectroscopy as shown in Figure 4 [14].

The significance of this technique is tailoring the defect chemistry without sacrificing the surface area and the optimum polymorphic composition. This crystallographic composition has also shown
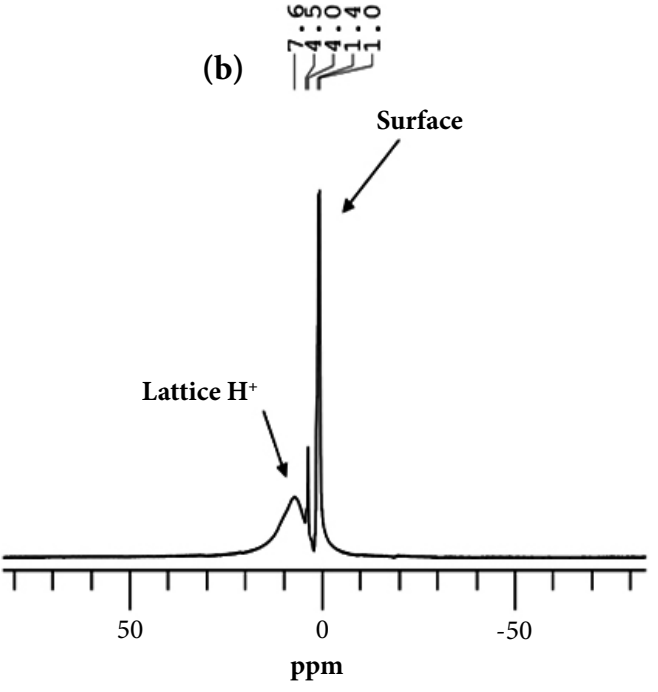

superior antimicrobial activity to single phase reference titanias [49]. The Br/An mixed phase titania is analogous to the An and $\mathrm{Ru}$ mixed phase in P25 as shown in Figure 5. The superior UV photocatalytic activity of P25 has been delineated by the efficient intercrystalline electron transport and charge separation by the minor rutile phase acting as the electron "antenna" [50]. Ozawa et al. [51] proposed strong coupling between $\mathrm{An}$ and $\mathrm{Ru}$ in their 


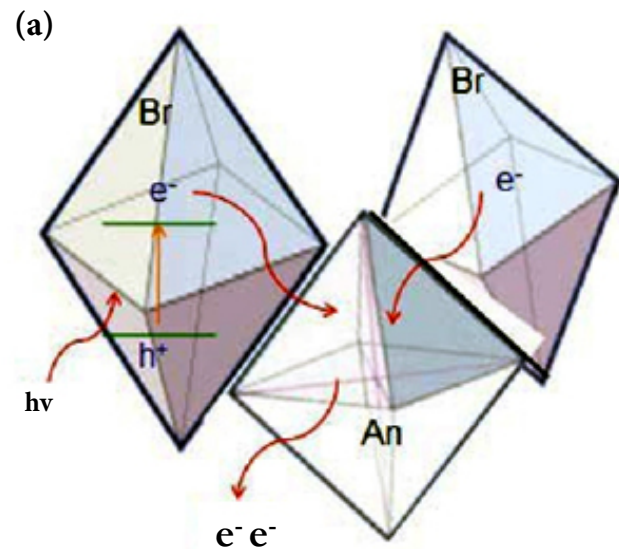

Surface (b)

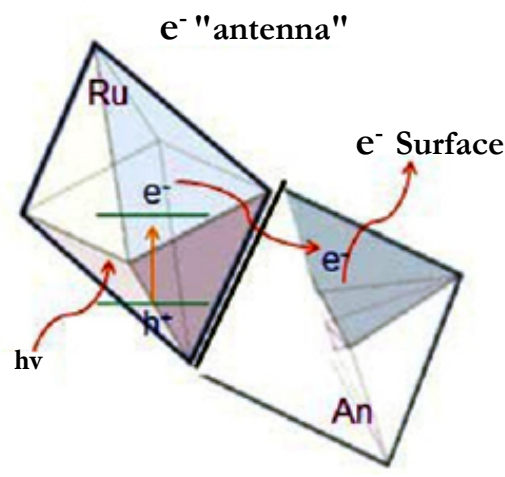

mixed phase titania. Xia et al. [52] supported the efficient charge separation in P-25 titania via molecular dynamic simulation and density functional theory along with Raman spectroscopy. Gai et al. [36] also showed superior PCA for an N-doped An/Br polymorph by efficient electron transport of the excited es from $\mathrm{Br}$ to An. The probable mechanism, analogous to the commercial reference titania P25, suggests an effective intergrain electron transfer and charge separation. This, in turn, reduced the electron-hole recombination rate $[12,13,35,36,39]$.

The importance of charge separation via heterojunction in photosemiconductors for a more efficient PCA has been emphasized by many researchers [20-29,50-52]. Xia et al. [52] showed by density of states computed by DFT that the band gap in a mixed phase titania decreased from $3.2 \mathrm{eV}$ of An to $2.0 \mathrm{eV}$ as the proportion of rutile phase increased up to about $50 \%$. Li et al. [40] presented $\mathrm{Br}$ having indirect band gap energy of $2.85 \mathrm{eV}$. These suggest the band gap of $\mathrm{Br} / \mathrm{An}$ polymorph is significantly below that of $\mathrm{An}$ $(3.2 \mathrm{eV})$ to absorb VL.

As the calcination temperatures of PBT increased, $\mathrm{Br}$ and $\mathrm{An}$ in PBT transformed to Ru [11]. Also as Ru phase increased and $\mathrm{Br}$ phase decreased in the polymorph, the VLA decreased [33]. Postech sample, which is a hydrothermal nitrogen doped single phase An, absorbed some VL as shown in Figure 2 of UV/Vis spectra. However, it was VL inactive under the $14 \mathrm{~W}$ VL source for MO degradation (Figure 3). SACS200 titania has shown to be superior to all other reference titanias in generating hydrogen from aqueous EDTA solution under VL [13]. Hydrogen generation rate from water was shown to follow the same trend as shown for MO photocatalytic decomposition in Figure 3. HBK titania is a commercial anatase titania with the name Hombikat having SSA $>200 \mathrm{~m}^{2} / \mathrm{g}$. Despite the high surface area of HBK, the hydrogen generation under VL was only that of untreated PBT, which has SSA of $\sim 160 \mathrm{~m}^{2} / \mathrm{g}$. The crystallographic difference between HBK and PBT is the phase composition. HBK is fully An but PBTis An with more than 50\% brookite.

Therefore, the major contributing factors for the observed superior VL-PCA from the An/Br polymorphic SACS200 are listed as: (1) the lower lattice hydroxyl content [11-13], (2) nitrogen doping [12] from NMP for enhanced VL absorption, and (3) the effective charge separation and intergrain transfer of VL excited electrons from one phase to the other $[11-13,36]$. So several opportuni- ties to further enhance VL-PCA and photochemical reactions in titania are:

a) Tailoring the crystallography of polymorphic titania with respect to crystallographic phase composition during the synthesis, though the optimum phase composition is yet to be determined [13],

b) Deprotonation or dehydroxylation from the crystal lattice at a low temperature not losing the high SSA and without altering the optimum phase composition/distribution for the maximum PCA, and

c) Introducing or incorporating VL absorbing chromophore in titania that extracts the entrapped protons at the same time.

\section{References}

[1]. Chen X, Mao SS (2007) Titanium dioxide nanomaterials: synthesis, properties, modifications, and applications. Chem Rev 107: 2891-2959.

[2]. Zhou L, Deng J, Zhao Y, Liu W, An L, et al, (2009) Preparation and characterization of N-I co-doped nanocrystal anatase $\mathrm{TiO}_{2}$ with enhanced photocatalytic activity under visible-light irradiation Materials Chem and Physics 117: 522.

[3]. Chen X, Liu L, Yu PY, Mao SS (2011) Increasing solar absorption for photocatalysis with black hydrogenated titanium dioxide nanocrystals. Science. 331: 746-750

[4]. Kruth A, Antje Quade, Volker Brüser, Klaus-Dieter Weltmann (2013) Plasma-enhanced synthesis of poly(allylamine)-encapsulated ruthenium dyesensitized titania photocatalysts. J Phys Chem. C. 117: 3804-3811.

[5]. Lee CH, Shie JL, Tsai CY, Yang YT, Chang CY (2014) Photoelectrochemical characteristics of $\mathrm{N}$-and $\mathrm{S}$-doped $\mathrm{TiO}_{2}$ with coumarin. Journal of Clean Energy Technologies 2: 38-42.

[6]. Li Z, Fang Y, Zhan X, Xu S (2013) Facile preparation of squarylium dye sensitized $\mathrm{TiO}_{2}$ nanoparticles and their enhanced visible-light photocatalytic activity. Journal of Alloys and Compounds 564:138.

[7]. Chen Q, Shi H, Shi W, Xu Y, Wu D (2012) Enhanced visible photocatalytic activity of titania-silica photocatalysts: effect of carbon and silver doping. Catal Sci Technol 2: 1213-1220.

[8]. Seery MK, George R, Floris P, Pillai SC (2007) Silver doped titanium dioxide nanomaterials for enhanced visible light photocatalysis. Journal of Photochemistry and Photobiology A: Chemistry. 189: 258-263.

[9]. Kuhn JN, Qayyum E, Castillo VA, Warrington K, Barakat MA (2013) Immobilization of silver-based bimetallic nanoparticles on titania-support for photocatalysis . J. of Physics: Conference Series. 431: 012020.

[10]. Dunnill CW, Ansari Z, Kafizas A, Perni S, Morgan DJ, et al, (2011) Visible light photocatalysts-N-doped $\mathrm{TiO}_{2}$ by sol-gel, enhanced with surface bound silver nanoparticle islands. J Mater Chem. 21: 11854-11861.

[11]. Lee BI, Wang XY, Bhave R, Hu M (2006) Synthesis of brookite TiO nanoparticles by ambient condition sol process. Mater Lett. 60: 1179-1182.

[12]. Sujaree Kaewgun, Daniel Mckinney, Jamie White, Andrew Smith, Michael Tinker, et al. (2009) Study of visible light photocatalytic activity achieved by NMP solvent treatment of polymorphic titania. J of Photochem \& Photobio. A: Chemistry. 202: 154-158. 
[13]. Lee BI, Kaewgun S, Kim W, Lee J, Choi W (2009) Visible light photocatalytic properties of polymorphic brookite titania. J Renew \& Sustainable Energy.1: 023101.

[14]. Kaewgun S, Nolph CA, Lee BI, Wang LQ (2009) Influence of hydroxyl contents on photocatalytic activities of polymorphic titania nanoparticles. Mater Chem Phys.114: 439-445.

[15]. Sato T, Aita Y, Komatsu M, Yin S (2006) Solvothermal synthesis of visible light responsive nitrogen-doped titania nanocrystals. J Mater Sci. 41: 14331438.

[16]. Yin S, Sato T (2000) Synthesis and photocatalytic properties of fibrous titania prepared from protonic layered tetratitanate precursor in supercritical alcohols. Ind Eng Chem Res. 39: 4526-4530.

[17]. Yin S, Fujishiro Y, Wu JH, Aki M, Sato T (2003) Synthesis and photocatalytic properties of fibrous titania by solvothermal reactions. J Mater Process Technol. 137: 45-48.

[18]. Yin S, Inoue Y, Uchida S, Fujishiro Y, Sato T (1998) Crystallization of titania in liquid-media and photochemical properties of crystallized titania. J Mater Res. 13: 844.

[19]. Yin S, Aita Y, Komatsu M, Wang JS, Tang Q, et al, (2005) Synthesis of excellent visible-light responsive $\mathrm{TiO}_{2}-\mathrm{xNy}$ photocatalyst by a homogeneous precipitation-solvothermal process. J Mater Chem.15: 674-682.

[20]. Cowan SR, Roy A, Heeger AJ (2010) Recombination in polymer-fullerene bulk heterojunction solar cells. Phys Rev B. 82: 245207.

[21]. Reusch M, Bivour M, Hermle M, Glunz SW (2013) Fill factor limitation of silicon heterojunction solar cells by junction recombination. Energy Procedia. 38: 297-304.

[22]. Zhou S, Sun J, Zhou C, Deng Z (2013) Comparison of recombination models in organic bulk heterojunction solar cells. Physica B: Condensed Matter. 415: 28-33.

[23]. Ishihara H, Kannarpady GK, Woo J, Biris AS (2013) Enhanced photocurrent response of titania-nanotube hetero junction devices capped with titanium disilicide. Energy Technology. 1: 412-418.

[24]. Etacheri V, Michlits G, Seery MK, Hinder SJ, Pillai SC (2013) A highly efficient $\mathrm{TiO}_{(2-x)} \mathrm{C}(\mathrm{x})$ nano-heterojunction photocatalyst for visible light induced antibacterial applications. ACS Appl Mater Interfaces. 5: 1663-1672.

[25]. Avasthi S, McClain WE, Man G, Kahn A, Schwartz J, et al, (2013) Holeblocking titanium-oxide/silicon heterojunction and its application to photovoltaics. Appl. Physic Letters. 102: 203901.

[26]. Zhang J, Zhu Z, Tang Y, Müllen K, Feng X (2014) Titania nanosheet-mediated construction of a two-dimensional titania/cadmium sulfide heterostructure for high hydrogen evolution activity. Adv Mater. 26: 734-738.

[27]. Niraula M, Adhikari S, Lee DY, Kim EK, Yoon SJ, et al. (2014) Titania nanotube-silver phosphate hybrid heterostructure for improved visible light induced photocatalysis. Chemical Physics Letters. 593: 193-197.

[28]. Haruta M, Yamada N, Kobayashi T, Iijima S (1989) Gold catalysts prepared by coprecipitation for low-temperature oxidation of hydrogen and of carbon monoxide. J Catal. 115: 301-309.

[29]. Haruta M, Date M (2001) Advances in the catalysis of Au nanoparticles. Appl Catal. 222: 427-437.

[30]. Liu L, Ouyang S, Ye J (2013) Gold-nanorod-photosensitized titanium dioxide with wide-range visible-light harvesting based on localized surface plasmon resonance. Angew Chem Int Ed Engl. 52: 6689-6693.

[31]. Jianjun Guo, Shuxin Ouyang, Peng Li, Yuanjian Zhang, Tetsuya Kako, et al, (2013) A new heterojunction $\mathrm{Ag}_{3} \mathrm{PO}_{4} / \mathrm{Cr}-\mathrm{SrTiO}_{3}$ photocatalyst towards efficient elimination of gaseous organic pollutants under visible light irradiation. Appl Catal. 134: 286-292.

[32]. Tong H, Ouyang S, Bi Y, Umezawa N, Oshikiri M, et al, (2012) Nanophotocatalytic materials: possibilities and challenges. Adv Mater. 2012; 24:
229-251.

[33]. Bhave RC, Lee BI. (2007) Experimental variables for the formation of brookite phase $\mathrm{TiO}_{2}$ nanoparticles Mater Sci Eng. A 467: 146-149.

[34]. Kandiel TA, Robben L, Alkaim A, Bahnemann D (2013) Brookite versus anatase $\mathrm{TiO}_{2}$ photocatalysts: phase transformations and photocatalytic activities. Photochem Photobiol Sci. 12: 602-609.

[35]. Di Paola, Bellardita M, Palmisano L (2013) Brookite, the least known $\mathrm{TiO}_{2}$ photocatalyst. Catalysts. 3: 36-73.

[36]. Gai L, Duan X, Jiang H, Mei Q, Zhou G, et al. (2012) One-pot synthesis of nitrogen-doped $\mathrm{TiO}_{2}$ nanorods with anatase/brookite structures and enhanced photocatalytic activity Cryst Eng Comm. 14: 7662-7671.

[37]. Lin H, Li L, Zhao M, Huang X, Chen X, et al. (2012) Synthesis of highquality brookite $\mathrm{TiO}_{2}$ single-crystalline nanosheets with specific facets exposed: tuning catalysts from inert to highly reactive. J Am Chem Soc. 134: 8328-8331.

[38]. Kaewgun S, Nolph CA, Lee BI (2008) Enhancing photocatalytic activity of polymorphic titania nanoparticles by NMP solvent-based ambient condition process. Catalysis Letters. 123: 173-180.

[39]. Nolph CA, Sievers DE, Kaewgun S, Kucera CJ, McKinney DH, et al. (2007) Photocatalytic study of polymorphic titania synthesized by ambient condition sol process. Catalysis Letters.117: 102-106.

[40]. Li JG, Ishigaki T, Sun XD (2007) Anatase, brookite, and rutile nanocrystals via redox reactions under mild hydrothermal conditions: phase-selective synthesis and physicochemical properties. J Phys Chem C. 111: 4969.

[41]. Degussa, AEROXIDE and AEROPEAL (2005) Titanium dioxide as photocatalyst. Degussa Technical Information. 1243.

[42]. Joshi P, Richards B, Jha A (2013) Reduction of OH- ions in tellurite glasses using chlorine and oxygen gases. Journal of Materials Research. 28: 32263233

[43]. Maie H, Lee BI (2009) Hydroxyl effects on dielectric properties of nanoparticle barium titanate. J Mater Sci. Materials in Electronics. 20: 619-627.

[44]. Qi L, Lee BI, Badheka P, Wang LQ, Gilmour P, Samuels WD, Exarhos G] (2005) Low temperature paraelectric-ferroelectric phase transformation in hydrothermal $\mathrm{BaTiO}_{3}$ particles. Mater Lett. 59: 2794-2798.

[45]. Kota R, Lee BI (2007) Effect of lattice hydroxyl on the phase transition and dielectric properties of barium titanate particles. J Mater Sci. Electronics 18: 1221-1227.

[46]. Badheka P, Magadala V, Devaraju NG, Lee BI, Kim ES (2006) Effect of dehydroxylation of hydrothermal barium titanate on dielectric properties in polystyrene composite. J Appl Polymer Sci. 99: 2815-2821.

[47]. Nam CT, Yang WD, Duc L (2013) Solvothermal synthesis of TiO photocatalysts in ketone solvents with low boiling points. Journal of Nanomaterials, 627385 .

[48]. 48.Tong H, Umezawa N, Ye J (2011) Visible light photoactivity from a bonding assembly of titanium oxide nanocrystals. Chem Commun (Camb). 47:4219-4221.

[49]. Shah RR, Kaewgun S, Lee BI, Tzeng TR (2008) The antibacterial effects of biphasic brookite-anatase titanium dioxide nanoparticles on multiple-drugresistant staphylococcus aureus. J Biomedical Nanotechnology. 4: 339-349.

[50]. Hurum DC, Agrios AG, Gray KA, Rajh T, Thurnauer MC (2003) Explaining the enhanced photocatalytic activity of Degussa P25 mixed-phase $\mathrm{TiO}_{2}$ using EPR. J Phys Chem B. 107: 4545-4549.

[51]. OzawaT, Iwasaki M, Tada H, Akita T, Tanaka K, et al. (2005) Low-temperature synthesis of anatase-brookite composite nanocrystals: the junction effect on photocatalytic activity. J Colloid Interface Sci. 281: 510-513.

[52]. Xia T, Li N, Zhang Y, Kruger MB, Murowchick J, et al. (2013) Directional heat dissipation across the interface in anatase-rutile nanocomposites. ACS Appl Mater Interfaces. 5: 9883-9890. 